\title{
Open distal anastomosis in aortic root replacement using axillary cannulation and moderate hypothermia
}

\author{
Hiroo Takayama, MD, Craig R. Smith, MD, Michael E. Bowdish, MD, and Allan S. Stewart, MD
}

\begin{abstract}
Objective: Recent advance in surgical technique facilitates more aggressive approaches for thoracic aortic diseases. We sought to address the outcomes of our strategy of open distal anastomosis with aortic root replacement using axillary cannulation and moderate hypothermia.
\end{abstract}

\begin{abstract}
Methods: A retrospective review of 228 patients who underwent aortic root replacement between July 2004 and December 2007 was performed.

Results: Axillary artery cannulation was successful in $98 \%$ of the attempted cases and resulted in no adverse events in $97 \%$. The axillary artery was the site of arterial cannulation in $89 \%$ of the cases, among which 136 patients $(60 \%$ of the cases) underwent an open distal anastomosis, consisting of the cohort of interest. Median age of the patients was 60 years (ranging from 16 to 89 years) with $79 \%$ being male. The principal diagnosis for the operation included aneurysmal disease without aortic dissection (78\%), type A aortic dissection with or without aneurysm (12\%), and endocarditis (5.9\%). Performed operations were modified Bentall operation (53\% of the cohort), valve-sparing aortic root replacement $(26 \%)$, and replacement with a homograft $(20 \%)$. Hemiarch replacement was added in $43 \%$. Mean \pm standard deviation of the lowest temperature was $27^{\circ} \mathrm{C}$ $\pm 2.6^{\circ} \mathrm{C}$. There were 5 deaths (mortality $\left.3.7 \%\right)$. A total of 16 patients $(12 \%)$ had major complications.
\end{abstract}

Conclusions: Open distal anastomosis at the time of aortic root replacement can safely be performed with axillary artery cannulation and moderate hypothermia. Axillary cannulation provides a reliable route of antegrade cerebral perfusion and enables the complex procedure to be performed without deep hypothermic circulatory arrest.

With recent improvement in surgical technique, a more aggressive surgical approach has been advocated in a variety of thoracic aortic diseases. ${ }^{1-3}$ We believe this trend holds true even in aortic root surgery, which requires sound understanding of the pathophysiology/anatomy and remains one of the most technically challenging operations in cardiovascular surgery. Concomitantly replacing the more distal aorta with this complex root operation, however, will place the patient at a much higher risk, especially if deep hypothermic circulatory arrest is used.

The more extended replacement was liberally added to the aortic root replacement at the Aortic Surgery Program of our institution, and this was accomplished by open distal anastomosis. Cerebral protection was achieved by selective antegrade cerebral perfusion through axillary artery cannulation and only moderate hypothermia was used. Avoiding deep hypothermic circulatory arrest, the adoption of this means of cerebral protection at the aortic root replacement enabled us to safely replace the entire ascending aorta, which not uncommonly is diseased in patients who have aortic root disease. In the present study, we addressed the outcomes of our current strategy.

From the Division of Cardiothoracic Surgery, Columbia University, New York, NY. Received for publication July 28, 2008; revisions received Oct 16, 2008; accepted for publication Nov 19, 2008.

Address for reprints: Allan S. Stewart, MD, NewYork-Presbyterian Hospital/Columbia, Milstein Hospital Bldg, Room 7-435, 177 Fort Washington Ave, New York, NY10032 (E-mail: as2276@columbia.edu).

J Thorac Cardiovasc Surg 2009;137:1450-3

$0022-5223 / \$ 36.00$

Copyright (c) 2009 by The American Association for Thoracic Surgery doi:10.1016/j.jtcvs.2008.11.027

\section{PATIENTS AND METHODS}

The study was approved by the institutional review board and informed consent was waived.

\section{Study Design}

This is a single center retrospective cohort study.

\section{Patient Selection}

All patients who underwent aortic root replacement, performed by our aortic surgeons (C.R.S. or A.S.S.), at Columbia University Medical Center over the interval of July 7, 2004, to December 5, 2007, were identified, consisting of the entire cohort. Among these, those who had an open distal anastomosis with an axillary artery cannulation were further selected out for the detailed analysis, consisting of the cohort of interest. Arterial cannulation site, technique of distal anastomosis, and the extent of replacement were determined by the attending surgeon on the basis of the quality of the distal ascending aorta: if it appeared normal without aneurysmal change, extensive atherosclerosis, or dissection, arterial cannulation was done centrally, the aorta was crossclamped, and the anastomosis was done in a closed fashion. Otherwise, an open distal anastomosis with peripheral arterial cannulation was performed.

\section{Data Abstraction}

The medical records of subjects were reviewed. We abstracted data including patient demographics, diagnosis for the operation, surgical procedures, concomitant procedures, procedural data, and outcomes of interest.

Outcomes of interest. The outcomes of interest in the current study included death, occurrence of major complications as well as any complications associated with axillary artery cannulation, and length of stay in the intensive care unit and the hospital.

Technique of right axillary artery cannulation. The arterial lines were inserted in the right radial artery and at another site (usually the left radial artery or femoral artery) for monitoring. A 3-cm incision was made just inferior to the right clavicle, at the junction of the middle and distal thirds. The incision was deepened with electrocautery, taking care not to 
TABLE 1. Site of the cannulation of the entire cohort

\begin{tabular}{lr}
\hline Total No. of cases & 28 \\
No. with axillary cannulation & 203 \\
Open distal anastomosis & 136 \\
Closed distal anastomosis & 67 \\
No. with central cannulation & 22 \\
No. with conversion from axillary to other site of cannulation & 3 \\
\hline
\end{tabular}

injure the brachial plexus. The right axillary artery was identified and dissected free for several centimeters. A 5000-IU dose of heparin was administered intravenously and the vessel was clamped. The artery was opened and an 8-mm Dacron graft was sewn end to side with 6-0 monofilament suture. A $24 \mathrm{~F}$ end-hole wire-wrapped aortic cannula was passed through the graft and secured in place with silk ties. The cannula was connected to the heart-lung machine and line pressure was tested before use.

Technique of root and ascending aorta replacement. After axillary artery cannulation, a median sternotomy was performed. Cardiopulmonary bypass was established with either a single atrial or bicaval cannula depending on the need for a concomitant procedure, and the patient was cooled to the targeted temperature. The mid-ascending aorta was crossclamped, the heart was arrested with cardioplegic solution, the aorta was opened, and the root replacement was completed first. Then bypass was terminated, the innominate artery was clamped, and the selective cerebral perfusion was begun with target flow rates of 10 to $15 \mathrm{~mL} \cdot \mathrm{kg}^{-2} \cdot \mathrm{min}^{-2}$ and a mean aortic pressure of $50 \mathrm{mmHg}$. The open distal anastomosis was performed, the clamp at the innominate artery was released, and flow was increased to full flow with rewarming. When a complex root operation, such as valve-sparing root replacement, was needed, a second graft was sewn to the opened distal aorta with selective cerebral perfusion, and then the clamp was moved to this second graft, and the graft-to-graft anastomosis was performed under full flow and rewarming.

\section{RESULTS}

\section{Patient Population}

Table 1 summarizes the entire cohort of our patients. A total of 228 aortic root replacements were performed during the study period. Eighty-nine percent $(n=203)$ of these patients had their operation with an axillary cannulation. Among these, 136 patients underwent the operation with an open distal anastomosis (60\% of the entire cohort), consisting of the cohort of interest. The attempt for axillary cannulation failed in 3 patients owing to inappropriate quality of the axillary artery (the axillary artery was too small in 2 patients, and it was involved in the aortic dissection in 1 patient). In 1 patient, although the axillary artery was cannulated without any problem, adequate systemic flow could not be achieved through the cannula, and therefore central cannulation was added. The distal anastomosis, however, was performed under selective cerebral perfusion through the axillary cannula. This patient was included to our cohort of interest.

The decision not to use an axillary cannulation was made when the distal ascending aorta was clearly not involved in the disease process, when the axillary artery was involved in the disease (such as dissection), or when there were mechanical obstacles to access the right axillary artery (such as implantable devices).
TABLE 2. Demographics of the cohort of interest and principal diagnosis for the operation

\begin{tabular}{lc}
\hline Total No. of cases with axillary cannulation & 136 \\
Age (y, median: range) & $60: 16-89$ \\
Gender (male:female) & $107: 29$ \\
Diagnosis & \\
Root and/or ascending aneurysm & 106 \\
Type A dissection \pm aneurysm & 16 \\
Endocarditis & 8 \\
Other & 6 \\
\hline
\end{tabular}

\section{Patient Demographics and Diagnosis}

Table 2 shows the demographics of the cohort of interest. Median age of the patients was 60 years (ranging from 16 to 89 years). Seventy-nine percent of the patients were male. The principal diagnosis for the operation included aneurysmal disease without aortic dissection (78\%), type A aortic dissection with or without aneurysm (12\%), and endocarditis $(5.9 \%)$.

\section{Procedure Performed for the Cohort of Interest}

A modified Bentall operation was performed in 72 (53\%) patients. Valve-sparing aortic root replacement was applicable in $36(26 \%)$. A homograft was used in 28 (20\%), mainly for extensive endocarditis.

Of note, in $43 \%$ of patients, hemiarch replacement was added to the root replacement, reflecting our aggressive approach (Table 3).

Means \pm standard deviation of cardiopulmonary bypass, aortic crossclamp, and selective cerebral perfusion times were $151 \pm 37,108 \pm 29$, and $12 \pm 6.5$ minutes, respectively. Lowest temperature achieved for the operation was $27^{\circ} \mathrm{C} \pm 2.6^{\circ} \mathrm{C}$ (mean \pm standard deviation).

\section{Outcomes of the Cohort of Interest}

Medians (range) of intensive care unit and hospital stay were 1 (1-56) and 6 (3-69) days. There were 5 deaths with a mortality rate of $3.7 \%$. The cause of death was respiratory failure in 3 , pulmonary embolism in 1 , and multiple organ failure in 1 . A total of $16(12 \%)$ patients, excluding the patients who died, had major complications, as shown in Table 4. No spinal cord injury was observed.

TABLE 3. Concomitant procedures

\begin{tabular}{lr}
\hline Reoperation & 18 \\
Hemiarch replacement & 59 \\
Other concomitant procedures & 28 \\
ASD/PFO closure & 3 \\
Mitral repair/replacement & 8 \\
CABG & 13 \\
Maze & 4 \\
Others & 3 \\
\hline
\end{tabular}

$\overline{A S D \text {, Atrial septal defect; } P F O \text {, patent foramen ovale; } C A B G \text {, coronary artery bypass }}$ grafting. 
TABLE 4. Postoperative outcomes of interest

\begin{tabular}{lc}
\hline ICU stay (day, median: range) & $1: 1-56$ \\
Hospital stay (day, median: range) & $6: 3-69$ \\
Mortality & $5(3.7 \%)$ \\
Major complications & $16(12 \%)$ \\
Respiratory failure & 3 \\
Wound infection & 3 \\
Pericardial effusion & 3 \\
Stroke & 2 \\
Pacemaker implantation & 2 \\
Others & 3 \\
Axillary cannulation complications & $4(2.9 \%)$ \\
Right arm weakness owing to brachial plexus injury & 1 \\
Right arm edema & 1 \\
Seroma & 1 \\
Right arm pain & 1 \\
\hline
\end{tabular}

$I C U$, Intensive care unit.

Among 228 of the entire cohort, axillary artery cannulation was attempted in 139 patients, and it was successful in 136 patients with a success rate of $98 \%$. Complications associated with axillary cannulation included brachial plexus injury (1 patient), right arm edema (1), seroma formation (1), and right arm pain (1) (Table 4). Axillary cannulation resulted in no adverse events in $97 \%$ of patients.

\section{DISCUSSION}

In the present study, we showed the following:

1. Our aggressive approach using open distal anastomosis for aortic root replacement resulted in satisfactory outcomes.

2. Axillary artery cannulation was safe and reliable.

By showing the above, our study implies that adding ascending or hemiarch replacement to aortic root replacement, which in itself is complex, can safely be attained with our strategy: open distal anastomosis under moderate hypothermia with selective antegrade cerebral perfusion through axillary artery cannulation. This result supports the current trend toward more aggressive replacement in aortic surgery.

Two surgical techniques have been used for anastomosis between a graft and a distal aorta in the aortic root and/or ascending aortic replacement. "Closed distal anastomosis" is performed with the distal ascending aorta clamped. In contrast, "open distal anastomosis" is created while the distal end of the aorta is left open, and this was advocated by the group of Livesay and associates. ${ }^{4}$ Compared with the closed technique, the open technique facilitates a technically more meticulous anastomosis, which contributes to avoidance of excess bleeding and prevents crowding and distortion around the anastomosis. More extensive replacement, such as hemiarch replacement, becomes possible. It also enables inspection of the arch and helps determine the appropriate extension of the aorta to be replaced, especially in dealing with an aortic dissection. Prevention of "clamp injury" by avoiding aortic crossclamping distal to the distal anastomosis is another important beneficial aspect of the open technique.

Despite all of these theoretical benefits from this technique, debate still persists regarding the optimal technique of distal anastomosis in replacing the ascending aorta. ${ }^{4-7}$ This contradiction is at least in part due to the detrimental effect of deep hypothermic circulatory arrest, which had been almost exclusively needed for open anastomosis. ${ }^{8,9}$ The detrimental consequence of deep hypothermia and circulatory arrest might offset the beneficial effect of open anastomosis over closed anastomosis.

One of the recent advancements of aortic surgery is the establishment of the concept of selective antegrade cerebral perfusion. ${ }^{10,11}$ Assuring some antegrade flow to the brain, surgeons can safely lay the aortic arch open under only mild to moderate hypothermia for a longer period of time. Avoiding deep hypothermia and circulatory arrest with selective cerebral perfusion, the open distal anastomosis technique now might be able to show its clinical advantage over the closed anastomosis technique. In the present study, in fact, the outcomes of our strategy were shown to be satisfactory with a mortality of $3.7 \%$ and a stroke rate of $1.5 \%$.

Our strategy might provoke concern about the complications associated with axillary artery cannulation, which is avoidable with the closed anastomosis technique or with the traditional open anastomosis technique with arterial cannulation to the aorta or other peripheral artery. Our result seems to support the reliability and safety of this technique. Axillary cannulation was feasible in $98 \%$ of the attempted cases. Ninety-seven percent of the patients were free from complications associated with axillary cannulation. Our finding is consistent with previous observations by others. ${ }^{7,12-21}$ Strauch and colleagues ${ }^{20}$ reported the experience at the Mount Sinai Medical Center, including a total of 284 patients. In $93 \%$, the right axillary artery was cannulated. Complications included $20.7 \%$ cases of brachial plexus injury (1 transient) and $3(1 \%)$ of localized dissection.

Interestingly, superiority of axillary artery cannulation compared with other site of cannulation was demonstrated by Svensson and coworkers ${ }^{21}$ from the Cleveland Clinic. They included 299 patients who had an axillary or subclavian artery cannulation with a side graft. Compared with patients with axillary/subclavian inflow with a side graft, the incidence of stroke was higher in patients with direct aortic cannulation (471 patients), and hospital mortality was higher in patients with femoral cannulation (375 patients). A similar result was shown in a retrospective review of 106 patients with acute type A dissection. ${ }^{16}$ The absence of axillary artery perfusion was shown to be an independent preoperative and intraoperative predictor of hospital death $(P=.0014$, odds ratio 8.2 ). 
Our study has several limitations. First, this is an analysis of retrospectively performed case series. Like all other retrospective studies, our study is not free from possible multiple biases. Our current strategy was not compared with any other strategies, such as conventional means of brain protection with deep hypothermic circulatory arrest, because we thought that it would have resulted in the comparison of the different patient populations or of the historical groups with which many factors including surgeons, available instruments, and so on, were different. Moreover, we believe that the outcomes of our series are sufficient to prove the efficacy of our strategy even without the control group. The applicability of our strategy to the other institutions/surgeons cannot be validated on the basis of the current study. It is, however, of importance to accumulate evidence from the experience of experts in discussing highly specialized areas, such as specific surgical technique. Second, we addressed only the early results of our strategy. Although the chart of each patient was extensively reviewed, the records after patients were discharged from the hospital were not always complete inasmuch as many of our patients were followed up at other facilities.

In conclusion, open distal anastomosis at the time of aortic root replacement can safely be performed using axillary cannulation and moderate hypothermia. Axillary cannulation provides a reliable route of antegrade cerebral perfusion and enables the complex procedure to be performed without deep hypothermic circulatory arrest.

\section{References}

1. Watanuki H, Ogino H, Minatoya K, Matsuda H, Sasaki H, Ando M, et al. Is emergency total arch replacement with a modified elephant trunk technique justified for acute type A aortic dissection? Ann Thorac Surg. 2007;84:1585-91.

2. Kouchoukos NT, Mauney MC, Masetti P, Castner CF. Single-stage repair of extensive thoracic aortic aneurysms: experience with the arch-first technique and bilateral anterior thoracotomy. J Thorac Cardiovasc Surg. 2004;128:669-76.

3. Sasaki H, Ogino H, Matsuda H, Minatoya K, Ando M, Kitamura S. Integrated total arch replacement using selective cerebral perfusion: a 6-year experience. Ann Thorac Surg. 2007;83:S805-10.

4. Livesay JJ, Cooley DA, Duncan JM, Ott DA, Walker WE, Reul GJ. Open aortic anastomosis: improved results in the treatment of aneurysms of the aortic arch. Circulation. 1982;66(2 Pt 2):I122-7.
5. Danner BC, Natour E, Horst M, Dikov V, Ghosh PK, Dapunt OE. Comparison of operative techniques in acute type A aortic dissection performing the distal anastomosis. J Card Surg. 2007;22:105-10.

6. Lai DT, Robbins RC, Mitchell RS, Moore KA, Oyer PE, Shumway NE, et al. Does profound hypothermic circulatory arrest improve survival in patients with acute type a aortic dissection? Circulation. 2002;106:I218-28.

7. Nguyen B, Müller M, Kipfer B, Berdat P, Walpoth B, Althaus U, et al. Different techniques of distal aortic repair in acute type A dissection: impact on late aortic morphology and reoperation. Eur J Cardiothorac Surg. 1999;15: 496-500.

8. Reich DL, Uysal S, Sliwinski M, Ergin MA, Kahn RA, Konstadt SN, et al. Neuropsychologic outcome after deep hypothermic circulatory arrest in adults. J Thorac Cardiovasc Surg. 1999;117:156-63.

9. Svensson LG, Crawford ES, Hess KR, Coselli JS, Raskin S, Shenaq SA, et al. Deep hypothermia with circulatory arrest: determinants of stroke and early mortality in 656 patients. $J$ Thorac Cardiovasc Surg. 1993;106:19-28.

10. Kazui T, Yamashita K, Washiyama N, Terada H, Bashar AH, Suzuki K, et al. Aortic arch replacement using selective cerebral perfusion. Ann Thorac Surg. 2007; 83:S796-8.

11. Kazui T, Inoue N, Yamada O, Komatsu S. Selective cerebral perfusion during operation for aneurysms of the aortic arch: a reassessment. Ann Thorac Surg. 1992; 53:109-14.

12. Di Eusanio M, Ciano M, Labriola G, Lionetti G, Di Eusanio G. Cannulation of the innominate artery during surgery of the thoracic aorta: our experience in 55 patients. Eur J Cardiothorac Surg. 2007;32:270-3.

13. Kestelli M, Yilik L, Ozsöyler I, Bozok S, Emrecan B, Pamuk B, et al. Aortic reoperations: experience with 23 patients using axillary artery cannulation. Int Heart J. 2005;46:1099-104.

14. Hedayati N, Sherwood JT, Schomisch SJ, Carino JL, Markowitz AH. Axillary artery cannulation for cardiopulmonary bypass reduces cerebral microemboli. $J$ Thorac Cardiovasc Surg. 2004;128:386-90.

15. Mazzola A, Gregorini R, Villani C, Di Eusanio M. Antegrade cerebral perfusion by axillary artery and left carotid artery inflow at moderate hypothermia. Eur J Cardiothorac Surg. 2002;21:930-1.

16. Moizumi Y, Motoyoshi N, Sakuma K, Yoshida S. Axillary artery cannulation im proves operative results for acute type a aortic dissection. Ann Thorac Surg. 2005; 80:77-83.

17. Sabik JF, Lytle BW, McCarthy PM, Cosgrove DM. Axillary artery: an alternative site of arterial cannulation for patients with extensive aortic and peripheral vascular disease. J Thorac Cardiovasc Surg. 1995;109:885-90.

18. Sabik JF, Nemeh H, Lytle BW, Blackstone EH, Gillinov AM, Rajeswaran J, et al. Cannulation of the axillary artery with a side graft reduces morbidity. Ann Thorac Surg. 2004;77:1315-20.

19. Schachner T, Vertacnik K, Laufer G, Bonatti J. Axillary artery cannulation in surgery of the ascending aorta and the aortic arch. Eur J Cardiothorac Surg. 2002;22: 445-7.

20. Strauch JT, Spielvogel D, Lauten A, Lansman SL, McMurtry K, Bodian CA, et al. Axillary artery cannulation: routine use in ascending aorta and aortic arch replacement. Ann Thorac Surg. 2004;78:103-8.

21. Svensson LG, Blackstone EH, Rajeswaran J, Sabik JF 3rd, Lytle BW, Gonzalez-Stawinski G, et al. Does the arterial cannulation site for circulatory arrest influence stroke risk? Ann Thorac Surg. 2004;78(4):1274-84. 